\title{
Novel microtubule-targeting agents, pyrrolo-1,5-benzoxazepines, induce cell cycle arrest and apoptosis in prostate cancer cells
}

\author{
SEEMA-MARIA NATHWANI ${ }^{1}$, SUZANNE M. CLOONAN ${ }^{1}$, MAEVE STRONACH ${ }^{1}$, GIUSEPPE CAMPIANI ${ }^{3}$, \\ MARK LAWLER $^{2}$, D. CLIVE WILLIAMS ${ }^{1}$ and DANIELA M. ZISTERER $^{1}$
}

\author{
${ }^{1}$ School of Biochemistry and Immunology, Trinity College, ${ }^{2}$ Institute of Molecular Medicine, St. James's Hospital and Trinity \\ College, Dublin 2, Ireland; ${ }^{3}$ European Research Centre for Drug Discovery and Development, Banchi di Sotto 55 \\ and Dipartimento Farmaco Chimico Tecnologico, Universita di Siena, via Aldo Moro 2, 53100 Siena, Italy
}

Received June 28, 2010; Accepted July 23, 2010

DOI: 10.3892/or_00001011

\begin{abstract}
Advanced hormone-refractory prostate cancer is associated with poor prognosis and limited treatment options. Members of the pyrrolo-1,5-benzoxazepine (PBOX) family of compounds exhibit anti-cancer properties in cancer cell lines (including multi-drug resistant cells), ex vivo patient samples and in vivo mouse tumour models with minimal toxicity to normal cells. Recently, they have also been found to possess anti-angiogenic properties in vitro. However, both the apoptotic pathways and the overall extent of the apoptotic response induced by PBOX compounds tend to be cell-type specific. Since the effect of the PBOX compounds on prostate cancer has not yet been elucidated, the purpose of this study was to investigate if PBOX compounds induce antiproliferative effects on hormone-refractory prostate cancer cells. We examined the effect of two representative PBOX compounds, PBOX-6 and PBOX-15, on the androgen-independent human prostate adenocarcinoma cell line, PC3. PBOX-6 and -15 displayed anti-proliferative effects on PC3 cells, mediated initially through a sustained $\mathrm{G}_{2} / \mathrm{M}$ arrest. $\mathrm{G}_{2} / \mathrm{M}$ arrest, illustrated as DNA tetraploidy, was accompanied by microtubule depolymerisation and phosphorylation of antiapoptotic proteins $\mathrm{Bcl}-2$ and $\mathrm{Bcl}-\mathrm{x}_{\mathrm{L}}$ and the mitotic spindle checkpoint protein BubR1. Phosphorylation of BubR1 is indicative of an active mitotic checkpoint and results in maintenance of cell cycle arrest. $\mathrm{G}_{2} / \mathrm{M}$ arrest was followed by apoptosis illustrated by DNA hypoploidy and PARP cleavage and was accompanied by degradation of BubR1, Bcl-2 and Bcl- $\mathrm{x}_{\mathrm{L}}$. Furthermore, sequential treatment with the CDK1inhibitor, flavopiridol, synergistically enhanced PBOXinduced apoptosis. In summary, this in vitro study indicates that PBOX compounds may be useful alone or in combination
\end{abstract}

Correspondence to: Dr Seema M. Nathwani, School of Biochemistry and Immunology, Trinity College, Dublin 2, Ireland E-mail: nathwans@tcd.ie

Key words: PBOX, microtubule-targeting agents, flavopiridol, prostate cancer with other agents in the treatment of hormone-refractory prostate cancer.

\section{Introduction}

Prostate cancer is the leading cause of cancer and the second leading cause of cancer-related deaths among men in Europe and the USA (1). Early diagnosis following widespread PSA screening has resulted in most patients presenting with localized tumours. These patients generally exhibit good survival rates following radiotherapy or surgery. However, a number of patients still progress to or are diagnosed with locally advanced or metastatic tumours. While androgendeprivation therapy can slow the development of advanced metastatic prostate cancer, most tumours will still progress within a few years to an androgen-independent state (2). At this stage, treatment options become limited. The current treatment of choice for patients with advanced hormonerefractory prostate cancer is docetaxel-based chemotherapy. While these treatments significantly improve the overall survival of patients $(3,4)$, the prognosis still remains poor for patients presenting with advanced stage prostate cancer. Therefore, the development of improved treatments and combinations are required.

Our research group have established that some members of the pyrrolo-1,5-benzoxazepine (PBOX) family of compounds are capable of inducing apoptosis in cancerous cell lines derived from both haematological malignancies [promyelocytic leukaemia HL60 cells, Jurkat T-lymphoma cells, Hut-78 lymphoma cells, T cell leukaemia CEM cells and chronic myeloid leukaemia (CML) K562 cells] and solid tumours (breast carcinoma MCF-7 cells and ovarian A2780 cells) (5-10). These results are supported by studies revealing impaired growth of tumours in a mouse 4T1 breast carcinoma tumour model (11), and a CML mouse model (12) and apoptosis in ex vivo CML and chronic lymphocytic leukaemia (CLL) patient samples $(12,13)$. Interestingly, these compounds exert only minimal toxicity to normal peripheral blood mononuclear cells (PBMCs) (8) or bone marrow cells (13). In addition, we have also found that PBOXs displayed antiangiogenic properties in vitro (10). An added advantage of PBOX compounds over many clinically used anti-cancer agents such as docetaxel is that they do not appear to be sub- 
strates of the $\mathrm{ABC}$-transporters, P-glycoprotein and BCRP, since they are capable of inducing apoptosis in multidrugresistant cancer cells expressing these transporters with similar efficacy as in transporter-negative drug-sensitive cells (14). The PBOX compounds exert their effects by binding to an uncharacterised site on tubulin resulting in microtubule depolymerisation (15). Our studies to date indicate that the mechanistic pathways downstream of tubulin depolymerisation and the overall extent of the apoptotic response tend to be cell-type specific. For example, we have shown that caspases are absolutely required for PBOX-induced apoptosis in promyelocytic leukaemia HL60 cells (5) but not in CML K562 cells (6). We have also elucidated that in response to PBOXtreatment, some cell types, such as K562 cells, exhibited a sustained mitotic arrest while other cell types, such as HL60 cells, arrested transiently and then proceeded to undergo apoptosis (16).

The effect of PBOX compounds on prostate cancer has not yet been documented. Therefore, in this study we examined the effect of two representative PBOXs, PBOX-6 and PBOX-15 (Fig. 1) on androgen-independent prostate cancer PC3 cells. We show that these compounds are capable of inhibiting proliferation of PC3 cells. This response was manifested by $\mathrm{G}_{2} / \mathrm{M}$ arrest followed by apoptosis. These events coincided with destabilisation of the microtubular network and phosphorylation followed by degradation of the anti-apoptotic proteins $\mathrm{Bcl}-2$ and $\mathrm{Bcl}-\mathrm{x}_{\mathrm{L}}$ and the mitotic spindle checkpoint protein BubR1. Furthermore, we also established that sequential treatment with CDK1 inhibitor, flavopiridol, synergistically enhanced PBOX-induced apoptosis in PC3 cells. Together with our previous findings these results indicate that PBOX compounds may prove to be useful agents in the treatment of hormone-refractory prostate cancer and therefore, are worthy of further investigation alone or in combination with other agents as potential treatments for advanced prostate cancer.

\section{Materials and methods}

Unless otherwise stated, chemicals were obtained from Sigma-Aldrich (Poole, Dorset, UK), antibodies from Merck Biosciences (Nottingham, UK) and tissue culture vessels were sourced from Greiner Bio-One GmbH (Frickenhausen, Germany).

Cell culture. Originally established from a bone metastasis of a grade IV human prostatic adenocarcinoma, PC3 cells, were obtained from the European Collection of Cell Cultures (Salisbury, UK). PC3 cells were maintained in Roswell Park Memorial Institute RPMI-1640 medium enhanced with GlutaMAX-I and supplemented with $10 \%$ foetal bovine serum (FBS), 50 units $/ \mathrm{ml}$ penicillin and $50 \mu \mathrm{g} / \mathrm{ml}$ streptomycin (all from Gibco, Invitrogen, Carlsbad, CA, USA). Cells were maintained in a humidified incubator at $37^{\circ} \mathrm{C}$ in $5 \% \mathrm{CO}_{2}$ and subcultured by trypsinisation upon reaching $\sim 80 \%$ confluency.

Reagents. The pyrrolo-1,5-benzoxazepine compounds, 7[(N,N-dimethylcarbamoyl)oxy]-6-(naphth-1-yl)pyrrolo [2,1-d] [1,5]benzoxazepine (PBOX-6), 4-acetoxy-5-(1-(naphthyl) naphtho[2,3-b]pyrrolo[2,1-d][1,4]oxazepine (PBOX-15) and

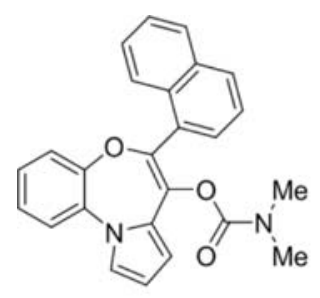

PBOX-6

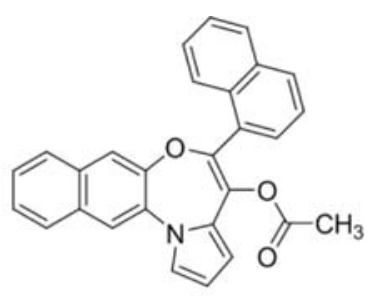

PBOX-15
Figure 1. Chemical structures of pyrrolo-1,5-benzoxazepines PBOX-6 and PBOX-15.

pyrrolobenzoxazepine 7-[(diethyl carbamoyl) oxy]-6-ptoylpyrrolo[2,1-d][1,5]benzoxazepine (PBOX-21) were synthesised as described previously (17) and dissolved in ethanol. The chemical structures of PBOX-6 and PBOX-15 are shown in Fig. 1. Paclitaxel and flavopriadol were dissolved in DMSO while vincristine was dissolved in water. Once reconstituted in the relevant solvent, all compounds were stored at $-20^{\circ} \mathrm{C}$ with the exception of flavopiridol which was stored at $4^{\circ} \mathrm{C}$.

Cell proliferation. Cell proliferation was monitored using AlamarBlue $^{\mathrm{TM}}$ dye (BioSource, Invitrogen, Carlsbad, CA, USA) which changes to a fluorescent state in the reduced environment of living cells. Cells $(20,000$ cells/well $)$ were seeded on 96-well plates for $24 \mathrm{~h}$ and then treated with a range of concentrations of PBOX-6 or PBOX-15 for $72 \mathrm{~h}$. Alamar-Blue [final concentration $10 \%(\mathrm{v} / \mathrm{v})$ ] was added and incubated at $37^{\circ} \mathrm{C}$. Fluorescence was measured at an excitation wavelength of $544 \mathrm{~nm}$ and an emission wavelength of $590 \mathrm{~nm}$ using a SpectraMax Gemini spectrofluorometric plate reader (Molecular Devices, Sunnyvale, CA). The results were expressed as the percentage cell viability relative to vehicle-treated control cells $(100 \%)$. Dose-response curves were plotted and $\mathrm{IC}_{50}$ values (concentration of drug resulting in $50 \%$ reduction in cell viability) were obtained using Prism GraphPad 4.

Determination of DNA content. Following treatment, adherent and non-adherent cells were harvested by trypinisation and centrifugation at $800 \mathrm{~g}$ for $10 \mathrm{~min}$. Cell pellets were resuspended in $200 \mu \mathrm{l}$ PBS and fixed by a drop-wise addition of $2 \mathrm{ml}$ of ice-cold $70 \%$ (v/v) ethanol/PBS while gently vortexing. Following overnight fixation at $-20^{\circ} \mathrm{C}$, the cells were centrifuged with $5 \mu \mathrm{l}$ FBS to remove the ethanol and resuspended in PBS supplemented with $0.5 \mathrm{mg} / \mathrm{ml}$ RNase A and $0.15 \mathrm{mg} / \mathrm{ml}$ propidium iodide (PI). Cells were incubated in the dark at $37^{\circ} \mathrm{C}$ for $30 \mathrm{~min}$. The PI fluorescence was measured on a linear scale using a FACSCalibur flow cytometer (Becton-Dickinson, San Jose, CA, USA). Data collections $(10,000$ events per sample) were gated to exclude cell debris and cell aggregates. PI fluorescence was proportional to the amount of DNA present in each entity and therefore, indicated the stage of the cell cycle. Cells in $G_{0} / G_{1}$ were diploid (2N DNA content), cells in the $S$ phase had DNA contents between $2 \mathrm{~N}$ and $4 \mathrm{~N}$, cells in $\mathrm{G}_{2} / \mathrm{M}$ were tetraploid (4N DNA content), while apoptotic cells were hypoploid and 
contained $<2 \mathrm{~N}$ DNA. The data was recorded and analysed using CellQuest software (Becton-Dickinson).

Microtubule staining by indirect immunofluorescence. PC3 cells $(80,000$ cell $/ \mathrm{ml})$, cultured on BD Falcon ${ }^{\mathrm{TM}}$ 4-chamber glass slides (BD Biosciences, San Jose, CA, USA) for $24 \mathrm{~h}$ were treated for $16 \mathrm{~h}$. The cells were fixed in $100 \%$ methanol at $-20^{\circ} \mathrm{C}(10 \mathrm{~min})$. The cells were then incubated in the following solutions, each incubation preceded by washing in PSB (Oxoid Ltd., Hampshire, UK): blocking solution [5\% $(\mathrm{w} / \mathrm{v})$ BSA dissolved in $0.1 \%(\mathrm{v} / \mathrm{v})$ Triton $\mathrm{X}-100$ in PBS] (30 min), monoclonal anti- $\alpha$-tubulin antibodies (Merck Biosciences, Nottingham, UK) (1 h), fluorescein isothiocyanate (FITC)-conjugated rabbit anti-mouse antibodies (Dako Cytomation, Glostrup, Denmark) $(1 \mathrm{~h})$ and $0.2 \mu \mathrm{g} / \mathrm{ml}$ propidium iodide ( $2 \mathrm{~min}$ ). The chamber partitions were removed from the slides and anti-quenching solution $(2 \mu \mathrm{g} / \mathrm{ml} p$-phenylenediamine in 50:50 glycerol to PBS solution) was applied to the surface of each slide and coverslips mounted. The organisation of the microtubule network (green) and the cellular DNA (red) was visualised under a $60 \mathrm{X}$ oil-emersion lens using an Olympus IX81 Fluorescent Microscope (Olympus Corp., Tokyo, Japan).

Analysis of protein expression and cleavage by Western blotting. Cells were harvested in whole cell lysis buffer containing $62.5 \mathrm{mM}$ Tris (pH 6.8), $2 \%$ (w/v) SDS, $10 \%$ (v/v) glycerol, $0.00125 \%(\mathrm{w} / \mathrm{v})$ bromophenol blue and $50 \mathrm{mM}$ DTT. The samples were then sonicated briefly and denatured at $65^{\circ} \mathrm{C}$ for $10 \mathrm{~min}$ before separation of proteins on a polyacrylamide gel and transfer to PVDF membrane. The PVDF transfers were probed with primary antibodies generated against PARP, BubR1 (BD Transduction Laboratories, Cowley, UK), Bcl-2, Bcl- $\mathrm{x}_{\mathrm{L}}$ or $\beta$-actin. This was followed by incubation with horseradish peroxidase-conjugated secondary antibodies (Promega, Madison, WI, USA). Protein expression was visualised by enhanced chemiluminescence.

Statistical analysis. Results were presented as mean \pm SEM. The statistical analysis of experimental data was performed using the computer program Prism GraphPad 4. P-values were determined using a two-tailed Student's paired t-test. A value of $\mathrm{P}<0.05$ was considered to be significant.

Analysis of drug interactions. Drug interactions were determined by median dose effect analysis using the computer program CalcuSyn (Biosoft, Cambridge, UK). This method is based on the drug effect equation of Chou and Talalay and can determine the degree of synergism or antagonism between two compounds by generating a combination index $(\mathrm{CI})$ value. CI values of $<1,=1$ and $>1$ indicate synergism, an additive effect and antagonism respectively (18).

\section{Results}

PBOX compounds reduced prostate cancer cell proliferation. Hormone-refractory prostate adenocarcinoma PC3 cells were treated for $72 \mathrm{~h}$ with a range of concentrations of PBOX-6 or PBOX-15. Cell proliferation was measured by AlamarBlue assay. PBOX-6 and -15 reduced proliferation of $\mathrm{PC} 3$ cells in a dose-dependent manner. PBOX-15 was found to be the most potent of the two analogues. $\mathrm{IC}_{50}$ values (concentration of drug resulting in $50 \%$ reduction in cell viability) were 5.8 and $0.37 \mu \mathrm{M}$ for PBOX-6 and -15 , respectively (Fig. 2A). The concentrations of drugs used for the remaining experiments were chosen to reflect the $\mathrm{IC}_{50}$ values obtained by this cell proliferation assay.

PBOX compounds induced $G_{2} / M$ arrest and apoptosis in prostate cancer cells. Flow cytometric analysis of propidium iodide staining allowed us to measure the DNA content of PC3 cells. PBOX-6 $(10 \mu \mathrm{M})$ and $-15(0.5 \mu \mathrm{M})$ induced statistically significant increases in the percentage of PC3 cells found in the $\mathrm{G}_{2} / \mathrm{M}$ phase (4N DNA content) of the cell cycle (Fig. 2B) which peaked for both compounds after $16 \mathrm{~h}$. In comparison to vehicle-treated PC3 cells, where only $26.6 \pm 1.6 \%$ of cells were found in the $\mathrm{G}_{2} / \mathrm{M}$ phase, $72.9 \pm 2.5 \%$ of cells were $\mathrm{G}_{2} / \mathrm{M}$ arrested following $16 \mathrm{~h}$ treatment with PBOX-6 $\left({ }^{* *} \mathrm{P}=0.0058\right)$ or $68.0 \pm 4.6 \%$ for PBOX-15 $\left({ }^{*} \mathrm{P}=0.0161\right)$. The levels of $\mathrm{G}_{2} / \mathrm{M}$ arrest dropped at later time points to $32.6 \pm 1.7 \%$ and $44.9 \pm 4.1 \%$ for PBOX-6 and -15 , respectively after $72 \mathrm{~h}$. This decline in the levels of $\mathrm{G}_{2} / \mathrm{M}$ arrest corresponded with significant increases in the amount of apoptotic cells (distinguished as cells displaying DNA hypoploidy, <2N DNA content) (Fig. 2C) with levels of apoptosis rising from $1.4 \pm 0.1 \%$ for vehicle-treated cells to $23.2 \pm 1.8 \%$ for $10 \mu \mathrm{M}$ P6 $\left({ }^{* *} \mathrm{P}=0.0068\right)$ and $18.2 \pm 1.8 \%$ for $0.5 \mu \mathrm{M}$ PBOX-15 ( $\left.{ }^{*} \mathrm{P}=0.0133\right)$ after $72 \mathrm{~h}$. These increases in DNA hypoploidy were accompanied by one of the key indicators of apoptosis, cleavage of the DNA repair enzyme PARP (Fig. 2D).

PBOX compounds resulted in destabilisation of the microtubule network in prostate cancer cells. PC3 cells were treated with PBOX-6 or -15 for $16 \mathrm{~h}$ (time of maximum $\mathrm{G}_{2} / \mathrm{M}$ arrest). As a positive control, cells were also treated with the known tubulin polymeriser, paclitaxel and the tubulin depolymeriser, vincristine. As a negative control, cells were treated with a non-apoptotic member of the PBOX family, the $\mathrm{G}_{1^{-}}$ arresting compound PBOX-21 (19,20). Immunofluorescent staining was used to detect morphological changes in the microtubule network, such as, alterations in organisation and arrangement (Fig. 3). In normal cells, the microtubule network is organised as cytoplasmic tubulin filaments radiating from a central point to the periphery. Cells treated with vehicle alone $(0.5 \%$ ethanol) displayed this typical tubulin morphology. Exposure of cells to the tubulin polymerising agent, paclitaxel, resulted in a highly concentrated accumulation of filaments into dense peripheral bundles indicative of microtubule stabilisation. The tubulin depolymerising agent, vincristine, resulted in diffuse tubule staining with no definition of structure caused by microtubule disassembly. While no change in microtubule structure was evident following treatment with the lower doses of $1 \mu \mathrm{M}$ PBOX-6 or $50 \mathrm{nM}$ PBOX-15, gross morphological changes in the tubulin cytoskeleton typical of depolymerising agents and visualised as diffuse tubule staining were observed when cells were treated with $10 \mu \mathrm{M}$ PBOX-6 or $0.5 \mu \mathrm{M}$ PBOX-15. As expected, exposure to the $\mathrm{G}_{1}$-arresting agent, PBOX-21 
(A)

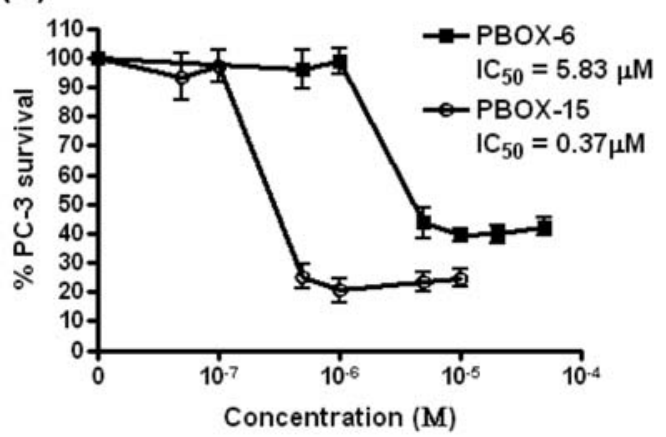

(C)

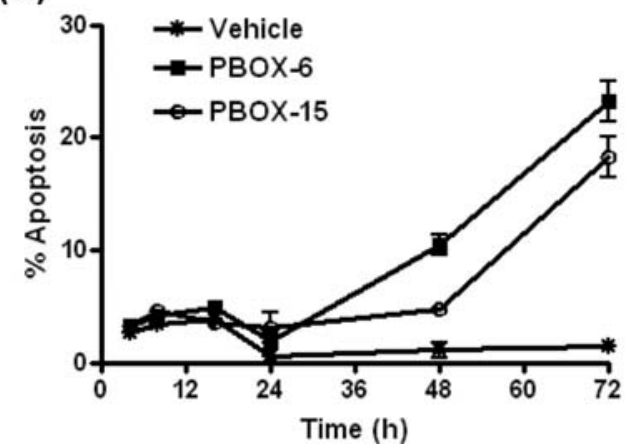

(B)

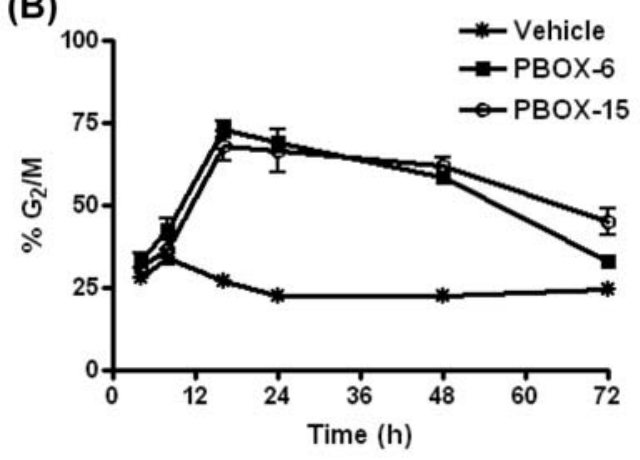

(D)

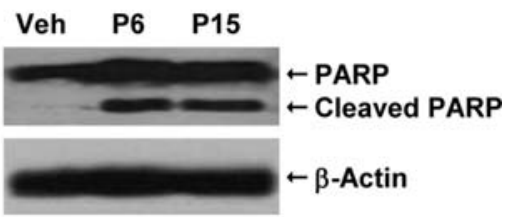

Figure 2. PBOX-6 and PBOX-15 reduced proliferation and induced $\mathrm{G}_{2} / \mathrm{M}$ arrest followed by apoptosis of hormone-refractory prostate carcinoma PC3 cells (A) PC3 cells were seeded onto 96-well plates and treated in triplicate with vehicle alone [1\% (v/v) ethanol] or a range of concentrations of PBOX-6 or PBOX-15 for $72 \mathrm{~h}$. The cells were then incubated in $10 \%$ (v/v) AlamarBlue ${ }^{\mathrm{TM}}$ and its reduction to a fluorescent state measured at excitation $544 \mathrm{~nm}$ and emission $590 \mathrm{~nm}$ using a multi-well fluorimeter. The results were expressed as the percentage cell proliferation relative to vehicle-treated control cells $(100 \%)$. Values represent the mean \pm SEM for three separate experiments. (B and C) PC3 cells were treated with vehicle [0.5\% (v/v) ethanol], PBOX-6 $(10 \mu \mathrm{M})$ or PBOX-15 $(0.5 \mu \mathrm{M})$ for up to $72 \mathrm{~h}$, fixed in ethanol, stained with propidium iodide and DNA content assessed by flow cytometry. Analysis of data was performed using the computer program CellQuest. Cells with $4 \mathrm{~N}$ quantities of DNA were considered to be in the $\mathrm{G}_{2} / \mathrm{M}$ phase of the cell cycle (B) while cells in the subG $\mathrm{G}_{0} / \mathrm{G}_{1}$ phase ( $<2 \mathrm{~N}$ DNA) were deemed apoptotic (C). Values represent the mean \pm SEM for three independent experiments. (D) PC3 cells were treated with vehicle [0.5\% (v/v) ethanol] (Veh), $10 \mu \mathrm{M}$ PBOX-6 (P6) or $0.5 \mu \mathrm{M}$ PBOX-15 (P15) for $72 \mathrm{~h}$. PARP cleavage was assessed by Western blot analysis using monoclonal antibodies generated against PARP or loading control B-actin, followed by HRP-conjugated anti-mouse secondary antibodies. Blots are representative of three independent experiments.
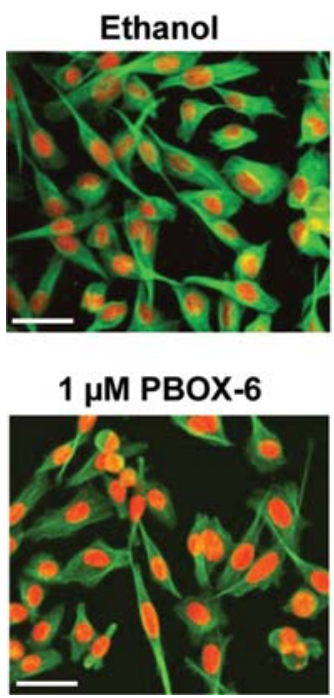

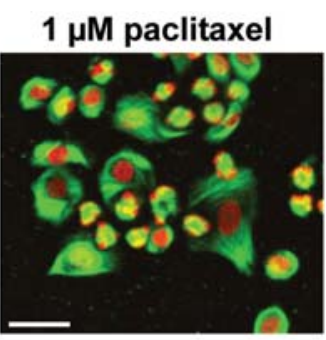

$10 \mu \mathrm{M}$ PBOX-6

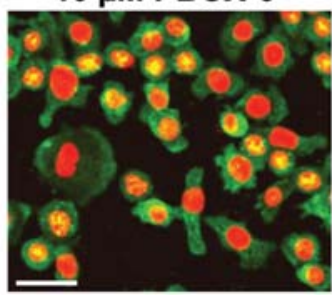

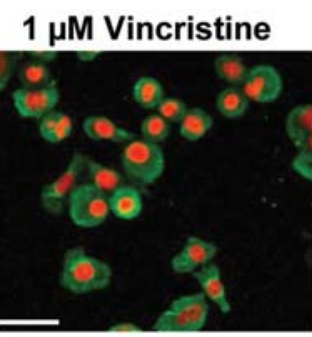

$50 \mathrm{nM}$ PBOX-15

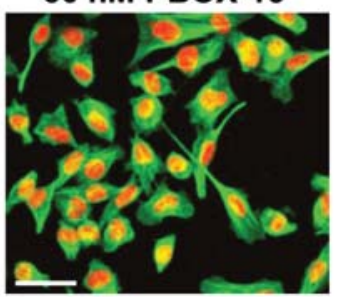

$25 \mu \mathrm{M}$ PBOX-21

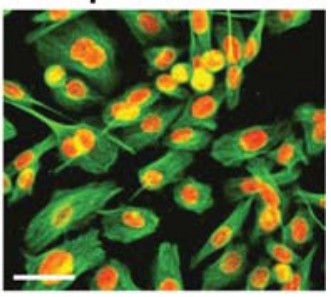

$0.5 \mu \mathrm{M}$ PBOX-15

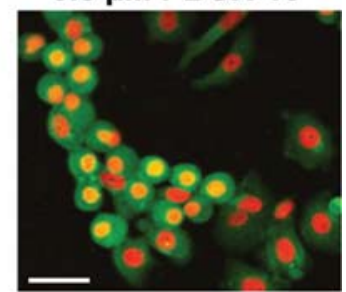

Figure 3. PBOX-6 and PBOX-15 resulted in disruption to the organisation of the microtubule network in PC3 cells. PC3 cells grown on 4-chamber glass slides were treated with the indicated doses of vehicle $[0.5 \%(\mathrm{v} / \mathrm{v}) \mathrm{EtOH}]$, paclitaxel, vincristine, PBOX-21, PBOX-6 or PBOX-15 for $16 \mathrm{~h}$. The cells were then fixed in methanol, incubated with monoclonal anti- $\alpha$-tubulin antibodies, followed by FITC-conjugated anti-mouse antibodies and then briefly stained with propidium iodide. The organisation of the microtubule network (green) and the cellular DNA (red) was visualised using a fluorescent microscope at a magnification of $\times 600$ (bar, $40 \mu \mathrm{m}$ ). The photographs are representative of three independent experiments. 
(A)

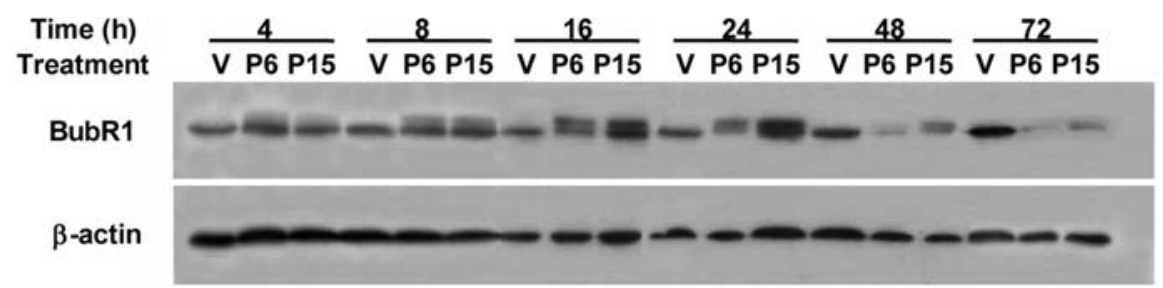

(B)

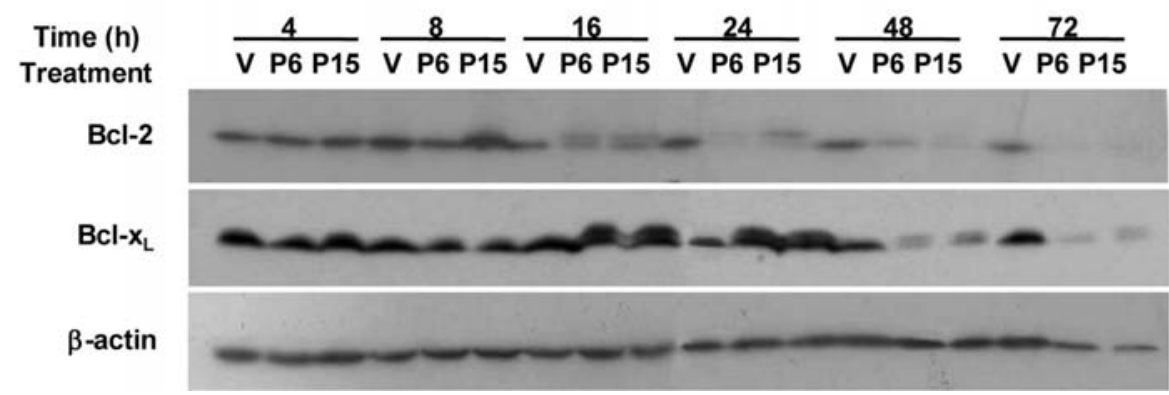

Figure 4. PBOX-6 and PBOX-15 induced phosphorylation followed by degradation of mitotic spindle checkpoint protein BubR1 and anti-apoptotic proteins Bcl-2 and Bcl- $\mathrm{x}_{\mathrm{L}}$ in PC3 cells. PC3 cells were treated with vehicle $[0.5 \%$ (v/v) EtOH] (V), $10 \mu \mathrm{M}$ PBOX-6 (P6) or 0.5 $\mu \mathrm{M}$ PBOX-15 (P15) for the indicated times. Protein phosphorylation was then assessed by Western blotting using primary antibodies for BubR1 (A), Bcl-2 (B), Bcl- $\mathrm{x}_{\mathrm{L}}$ (B) or $\mathrm{B}$-actin (loading control), followed by HRP-conjugated secondary antibodies. Blots are representative of three independent experiments.

$(25 \mu \mathrm{M})$, did not disrupt the microtubular network of PC3 cells and indicated that interference to the normal organisation of the microtubules is required for $\mathrm{G}_{2} / \mathrm{M}$ arrest in PC3 cells.

PBOX compounds induced phosphorylation followed by degradation of BubRI in prostate cancer cells. Treatment of PC3 cells with $10 \mu \mathrm{M}$ PBOX-6 or $0.5 \mu \mathrm{M}$ PBOX-15 resulted in a time-dependent phosphorylation of the mitotic spindle checkpoint protein BubR1 represented in Western blotting as the presence of a slower migrating band (Fig. 4A). Small amounts of phosphorylated BubR1 were evident as early as $4 \mathrm{~h}$ post-treatment and became most prominent after 16 and $24 \mathrm{~h}$. This hyperphosphorylation of BubR1 correlated to $\mathrm{G}_{2} / \mathrm{M}$ arrest and indicated an active mitotic checkpoint. At the later time point of $48 \mathrm{~h}$, levels of BubR1 decreased with very little BubR1 protein detectable after $72 \mathrm{~h}$, corresponding to a decline in $\mathrm{G}_{2} / \mathrm{M}$ and an increase in apoptosis. $\beta$-actin was used as a loading control.

PBOX compounds induced phosphorylation followed by degradation of Bcl-2 and Bcl- $x_{L}$ in prostate cancer cells. Treatment with $10 \mu \mathrm{M}$ PBOX-6 or $0.5 \mu \mathrm{M}$ PBOX-15 for $16 \mathrm{~h}$ resulted in phosphorylation of the anti-apoptotic proteins Bcl-2 and Bcl- $\mathrm{x}_{\mathrm{L}}$, again evidenced by a slower migrating band on a Western blot analysis (Fig. 4B). Levels of Bcl-2 began to decrease $24 \mathrm{~h}$ post-treatment with no Bcl-2 detectable after $72 \mathrm{~h}$ treatment. Phosphorylation of Bcl- $\mathrm{x}_{\mathrm{L}}$ was more sustained, since after $24 \mathrm{~h}$ the phosphorylated forms of $\mathrm{Bcl}-\mathrm{x}_{\mathrm{L}}$ were still prominent. However, levels of $\mathrm{Bcl}-\mathrm{x}_{\mathrm{L}}$ had declined by $48 \mathrm{~h}$ post-treatment. These results indicate that $\mathrm{Bcl}-2$ and $\mathrm{Bcl}-\mathrm{x}_{\mathrm{L}}$ are inactivated in prostate cancer cells by PBOX compounds. Again $ß$-actin was used as a loading control.
The CDK-1 inhibitor, flavopiridol, synergistically enhanced $P B O X$-induced apoptosis in prostate cancer cells. To investigate if the CDK-1 inhibitor flavopiridol could enhance the apoptotic efficacy of PBOX compounds in hormonerefractory prostate cancer cells, we treated PC3 cells with either vehicle $(0.5 \% \mathrm{EtOH}), \mathrm{PBOX}-6(1,5,10 \mu \mathrm{M})$ or PBOX-15 $(0.1,0.25,0.5 \mu \mathrm{M})$ for $18 \mathrm{~h}$ followed by treatment with either flavopiridol $(0.1,0.25,0.5 \mu \mathrm{M})$ for $24 \mathrm{~h}$ or fresh media (control). Apoptosis was quantified by flow cytometric analysis as the number of cells with hypoploid DNA content $(<2 \mathrm{~N}$ DNA). Treatment with vehicle for $18 \mathrm{~h}$ followed by treatment with flavopiridol $(0.5 \mu \mathrm{M})$ for $24 \mathrm{~h}$ resulted in a low level of apoptosis $7.2 \pm 0.2 \%$ compared to $2.7 \pm 1.0 \%$ with vehicle alone (Fig. 5A). Treatment with PBOX-6 (5 $\mu \mathrm{M})$ for $18 \mathrm{~h}$ followed by incubation in fresh media resulted in $11.9 \pm 3.0 \%$ apoptosis, while sequential treatment with flavopiridol $(0.5 \mu \mathrm{M})$ for $24 \mathrm{~h}$ after the PBOX-6 incubation step resulted in an increase in apoptosis to $18.2 \pm 1.5 \%$ (data not shown). PBOX-6 $(10 \mu \mathrm{M})$ for $18 \mathrm{~h}$ followed by incubation in fresh media resulted in $12.2 \pm 1.4 \%$ apoptosis whilst the same concentration of PBOX-6 followed by exposure to flavopiridol caused a statistically significant increase in apoptosis to $28.8 \pm 1.7 \%\left({ }^{*} \mathrm{P}=0.0264\right)$ (Fig. 5A). Similarly, sequential treatment with flavopiridol increased $0.25 \mu \mathrm{M}$ PBOX-15-induced apoptosis from $12.9 \pm 2.8 \%$ for PBOX-15 alone to $26.1 \pm 3.5 \%$ for the combination (data not shown) and caused a statistically significant increase in apoptosis from $15.1 \pm 0.5 \%$ for $0.5 \mu \mathrm{M}$ PBOX-15 alone to $32.4 \pm 2.3 \%$ for the combination $\left({ }^{*} \mathrm{P}=0.0274\right)$ (Fig. 5A).

To determine if the enhancement in apoptosis between flavopiridol and PBOX- 6 or -15 could be considered synergistic, we used the CalcuSyn program to perform a median dose analysis of our results. We found that flavopiridol $(0.5 \mu \mathrm{M})$ in combination with 5 or $10 \mu \mathrm{M}$ PBOX-6 was considered synergistic as they displayed combination index 


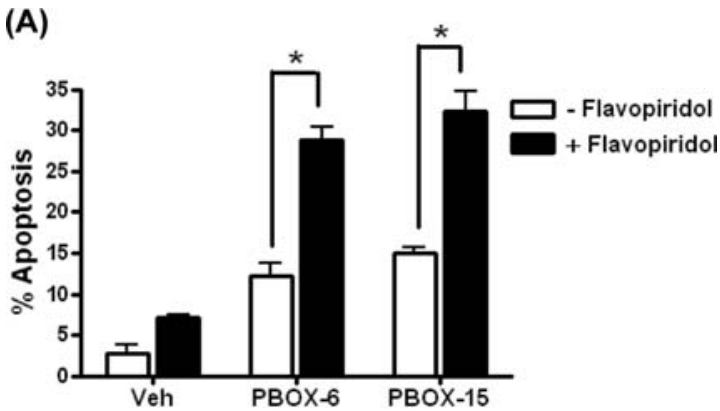

(B)

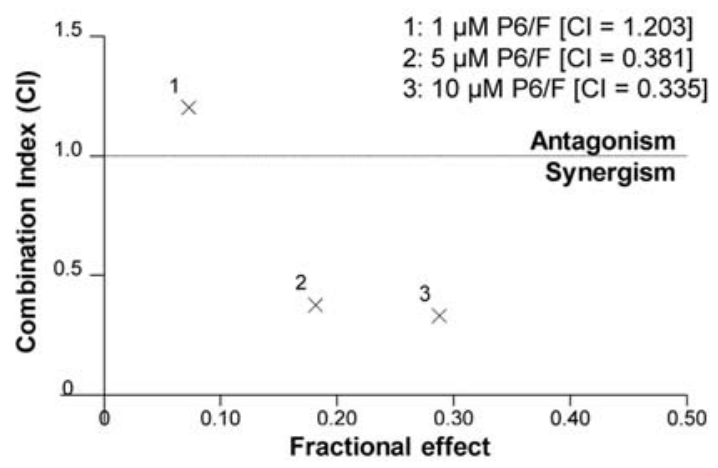

(C)

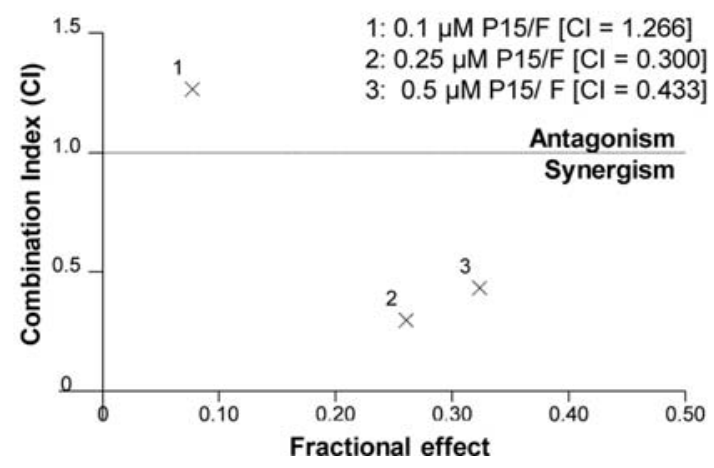

Figure 5. The CDK-1 inhibitor, flavopiridol, synergistically enhanced PBOX-induced apoptosis in PC3 cells. PC3 cells were treated for $18 \mathrm{~h}$ with vehicle $[0.5 \%(\mathrm{v} / \mathrm{v})$ ethanol], PBOX-6 $(1-5 \mu \mathrm{M})$ or PBOX-15 $(0.1-0.5 \mu \mathrm{M})$ followed by treatment for $24 \mathrm{~h}$ in either fresh media (as a control) or media containing flavopiridol $(0.1-0.5 \mu \mathrm{M})$. The cells were then fixed in ethanol, stained with propidium iodide and DNA content assessed by flow cytometry using CellQuest. Cells in the $\operatorname{subG}_{0} / \mathrm{G}_{1}$ phase $(<2 \mathrm{~N}$ DNA) were deemed apoptotic. Apoptosis induced by PBOX-6 $(10 \mu \mathrm{M})$ or PBOX-15 $(0.5 \mu \mathrm{M})$ alone or the same treatments followed subsequently by exposure to flavopiridol $(0.5 \mu \mathrm{M})$ was compared (A). Values represent the mean \pm SEM for three independent experiments $\left({ }^{*} \mathrm{P}<0.05\right)$. Median dose effect analysis was carried out using the software program CalcuSyn. Combination index (CI) values for varying concentrations of PBOX-6 (P6) (B) or PBOX-15 (P15) (C) in combination with $0.5 \mu \mathrm{M}$ flavopiridol (F) were generated. A CI value of $<1$ represents synergism while a CI value $>1$ represents antagonism.

(CI) values of $<1$ ( $\mathrm{CI}=0.381$ or 0.335 , respectively) (Fig. $5 \mathrm{~B}$ ). Similarly, flavopiridol in combination with 0.25 or $0.5 \mu \mathrm{M}$ PBOX-15 was found to be synergistic with CI values of 0.300 and 0.433 , respectively (Fig. 5C).
The lower concentrations of $1 \mu \mathrm{M}$ PBOX-6 and $0.1 \mu \mathrm{M}$ PBOX-15 in combination with flavopiridol resulted in only $7.3 \pm 1.6 \%$ and $7.7 \pm 0.7 \%$ apoptosis, respectively (data not shown), very similar to the amounts observed with flavopiridol alone (7.2\%). These concentrations of PBOX-6 and -15 alone were insufficient to produce any cell cycle effects in PC3 cells and indicated that the $\mathrm{G}_{2} / \mathrm{M}$ arresting properties of PBOXs were required for synergism with flavopiridol. As expected, these concentrations of PBOXs were not deemed by CalcuSyn to be synergistic with flavopiridol (Fig. 5B and C). In fact, median dose analysis actually graded these combinations as antagonistic (CI value $>1$ ) concluding that they produced a smaller than expected additive effect. However, this is because the program did not take into account the fact that the amount of apoptosis $(1.3 \%$ and $0.9 \%$ ) generated at these concentrations of PBOX-6 and -15 was merely background levels of apoptosis also found in vehicle-treated controls.

\section{Discussion}

The treatment of hormone-refractory advanced prostate cancer poses a significant challenge for clinicians. Until recently hormone-refractory prostate cancer was considered chemotherapy-refractory with the standard treatment of mitoxantrone plus prednisone merely providing palliative benefits. This theory was refuted in 2004 by clinical trials demonstrating that docetaxel plus prednisone (3) or docetaxel plus estramustine (4) significantly improved overall survival compared with mitoxantrone plus prednisone. Hence, the current standard of care for patients with this stage of prostate cancer is systemic chemotherapy with a docetaxel-based regimen (2). Unfortunately, over time, most patients still progress to develop resistance to docetaxel. Much of this resistance is thought to be mediated through expression of the multidrug-resistance transporter, P-glycoprotein or by microtubule alterations (21). In addition to inducing apoptosis in a variety of cancerous cell types (5-9) and impairing tumour growth in vivo $(11,12)$, novel pyrrolo-1,5-benzoxazepine $(\mathrm{PBOX})$ compounds possess the added benefit of inducing cytotoxicity in multidrug-resistant cancer cells expressing P-glycoprotein with similar potency as in P-glycoprotein-negative cancer cells (14). Furthermore, they appear to induce tubulin depolymerisation by binding to a novel as yet uncharacterized site on tubulin (15). To date, the effect of PBOX compounds on prostate cancer has not been examined. Hence, in this study we wished to perform some initial in vitro experiments to determine if PBOXs have any effect on advanced hormone-refractory prostate adenocarcinoma cells.

Herein, we report that $\mathrm{PBOXs}$ are capable of reducing cell proliferation of prostate cancer PC3 cells with $\mathrm{IC}_{50}$ values of $5.8 \mu \mathrm{M}$ for parent compound PBOX-6 and $0.37 \mu \mathrm{M}$ for its more potent analogue, $\mathrm{PBOX}-15$. These values are within a similar range (1-6 and 0.2-0.4 $\mu \mathrm{M}$ for PBOX-6 and -15, respectively) to those observed in other cell lines such as CML K562 cells, promyelocytic leukaemia HL60 cells, ovarian carcinoma A2780 cells and a range of mammary carcinoma cell lines $(10,11,14,16)$. This reduction in PC3 cell proliferation was mediated through a significant $\mathrm{G}_{2} / \mathrm{M}$ arrest 
which occurred concurrently with depolymerisation of the microtubular network. $\mathrm{G}_{2} / \mathrm{M}$ arrest was followed by a modest though significant amount of apoptosis. PBOX-15 induced slightly less apoptosis than PBOX-6 relating to a greater number of cells remaining in the $\mathrm{G}_{2} / \mathrm{M}$ phase and suggested PBOX-15 produced a slightly more sustained $\mathrm{G}_{2} / \mathrm{M}$ block than PBOX-6 at $72 \mathrm{~h}$. Progression to apoptosis induced by PBOXs in PC3 cells seemed to follow patterns previously observed in other cell types including CML K562 cells, HeLa cells and A2780 cells which also exhibited a sustained $\mathrm{G}_{2} / \mathrm{M}$ arrest followed by some apoptosis. In contrast, cell types such as HL60 and breast SK-BR-3 undergo only transient arrest followed by massive amounts of apoptosis $(10,14,16)$.

In order to delineate some of the mechanisms that may be involved in the response of PC3 cells to PBOX treatment, we examined some proteins which influence cell cycle arrest and apoptosis, namely, BubR1, Bcl-2 and Bcl- $\mathrm{x}_{\mathrm{L}}$. Firstly, we examined the mitotic spindle checkpoint protein BubR1, which monitors tension across attached kinetochores and initiates mitotic arrest in response to loss of microtubule tension (22). We have previously reported that expression of BubR1 directly relates to the length of time a cell remains in $G_{2} / M$, given that cells which expressed very little BubR1 such as HL60s underwent a very rapid transition from $\mathrm{G}_{2} / \mathrm{M}$ to apoptosis while cells such as K562s which highly expressed BubR1 remained arrested in $\mathrm{G}_{2} / \mathrm{M}$ much longer (16). Our DNA content analysis data demonstrated that PC3 cells remained in $\mathrm{G}_{2} / \mathrm{M}$ for quite a sustained period with some cells still remaining arrested after $72 \mathrm{~h}$, therefore, we decided to investigate if BubR1 is associated with this sustained arrest. Indeed, we found that initially BubR1 was hyperphosphorylated in PC3 cells treated with PBOX-6 or -15 . Hyperphosphorylation of BubR1 is indicative of an active mitotic checkpoint (23). Subsequently, expression of BubR1 declined at later time points corresponding to a decrease in the amount of cells undergoing $\mathrm{G}_{2} / \mathrm{M}$ arrest and an increase in apoptosis, indicating that the phosphorylation status of BubR1 in PC3 cells directly correlated to the quantities of $\mathrm{G}_{2} / \mathrm{M}$ arrest found in these cells. Therefore, we postulate that the expression of BubR1 in PC3 cells and its subsequent phosphorylation is likely to have contributed to the sustained arrest observed.

As microtubules have been shown to interact with mitochondria, it is thought that the mitochondria and their associated proteins connect microtubular insult to the apoptotic machinery (24). Mitochondrial anti-apoptotic proteins Bcl-2 and Bcl- $\mathrm{x}_{\mathrm{L}}$ are important in controlling apoptosis by preventing the release of mitochondrial pro-apoptotic factors, critical for cell death via the intrinsic apoptotic pathway. Overexpression of $\mathrm{Bcl}-2$ or $\mathrm{Bcl}-\mathrm{x}_{\mathrm{L}}$ is a common feature in many malignancies and confers resistance to a range of cytotoxic agents (25). Specifically, overexpression of Bcl-2 (26) and $\mathrm{Bcl}-\mathrm{x}_{\mathrm{L}}$ (27) are implicated in the development of hormone-resistance in prostate cancer cells. Overexpression of these proteins seems to block the events downstream of mitotic arrest that lead to apoptosis since $\mathrm{Bcl}-2$ or $\mathrm{Bcl}-\mathrm{x}_{\mathrm{L}}$ overexpression suppresses the apoptotic response of microtubule-targeting agents without affecting their actions on microtubules or their ability to induce $G_{2} / M$ arrest $(28,29)$.
We have previously demonstrated that PBOX-6 induces apoptosis in leukaemia cells overexpressing $\mathrm{Bcl}-2$ with similar potency as in leukaemia cells expressing normal levels of Bcl-2 (8). During this study we found that both PBOX-6 and -15 induced a transient phosphorylation of Bcl-2 and Bcl- $\mathrm{X}_{\mathrm{L}}$ which correlated to initiation of $\mathrm{G}_{2} / \mathrm{M}$ arrest in PC3 cells. Indeed, phosphorylation of $\mathrm{Bcl}-2$ is considered a marker of $M$ phase since it is also phosphorylated at $G_{2} / M$ phase of normally cycling cells (30). Following phosphorylation, expression of $\mathrm{Bcl}-2$ and $\mathrm{Bcl}-\mathrm{x}_{\mathrm{L}}$ diminished. These results adhere to an expected pattern of Bcl-2 and $\mathrm{Bcl}-\mathrm{x}_{\mathrm{L}}$ phosphorylation and inactivation since we have previously observed a similar effect in leukaemia cells whereby we found that phosphorylation and inactivation of $\mathrm{Bcl}-2$ and $\mathrm{Bcl}-\mathrm{x}_{\mathrm{L}}$ by the stress-activated protein kinase JNK (c-Jun N-terminal kinase) preceded PBOX-6-induced apoptosis (8). Furthermore, other studies have shown that phosphorylation of Bcl-2 is specifically induced by microtubule-targeting agents and not with DNA-damaging drugs and this phosphorylation is a prerequisite to inactivation/degradation of Bcl-2 (24).

Despite the fact that the PBOX- 6 and -15 induced a significant amount of apoptosis in PC3 cells after $72 \mathrm{~h}$, a number of cells still remained resistant to apoptosis. This phenomenon was associated with sustained $\mathrm{G}_{2} / \mathrm{M}$ arrest. Progression at the $\mathrm{G}_{2} / \mathrm{M}$ transition is regulated by a complex consisting of a regulatory subunit, cyclin B1 and a catalytic subunit cyclin-dependent kinase-1 (CDK-1) (31). Activation of the mitotic spindle checkpoint blocks the degradation of cyclin B1 and thus results in sustained activation of the cyclin B1/CDK-1 complex leading to $\mathrm{G}_{2} / \mathrm{M}$ arrest (24). We postulated that this sustained activation of the CDK1/cyclin B1 complex may play a role in the prolonged arrest observed in PC3 cells treated with PBOXs. Hence, we hypothesised that by reducing the activities of CDK-1 after the cells have already undergone $\mathrm{G}_{2} / \mathrm{M}$ arrest, we may increase the rate of apoptosis generated by PBOXs in PC3 cells. Indeed, we have previously reported that inhibition of CDK-1 by its inhibitor, flavopiridol enhanced PBOX-induced apoptosis in CML cells by accelerating exit from $\mathrm{G}_{2} / \mathrm{M}$ (32). Sequential treatment with flavopiridol is also reported to enhance effects of docetaxel in patients with advanced solid tumours (33). Therefore, we decided to investigate if flavopiridol was capable of enhancing PBOX-induced apoptosis in PC3 cells. As in CML cells, we found that flavopirdol administered as a sequential treatment after PBOX-induced $G_{2} / M$ arrest, synergistically enhanced apoptosis in PC3 cells compared to treatment with $\mathrm{PBOXs}$ alone.

Our results indicate that $\mathrm{PC} 3$ cells seem to respond to PBOX treatment in a similar manner to CML K562 cells, whereby they induce a sustained $\mathrm{G}_{2} / \mathrm{M}$ follow by a degree of apoptosis with many cells still remaining in $\mathrm{G}_{2} / \mathrm{M}$. In contrast, other cells types such as HL60s undergo a transient $\mathrm{G}_{2} / \mathrm{M}$ arrest followed by almost complete apoptosis in response to PBOXs. Since PC3 cells respond to PBOXs in a similar manner to CML K562 cells, it would be interesting to see if PBOXs would also behave similarly in an in vivo prostate tumour model to our in vivo CML mouse model in which tumour growth was successfully impaired by PBOX treatment (12). It would also be interesting to examine other 
combinations which may potentiate PBOX-induced apoptosis. For example, since skeletal metastases are commonly associated with advanced prostate cancer it may be useful to investigate a combination between PBOXs and with one of the anti-resorptive bisphosphonates such as zoledronic acid. This agent has already been found to enhance docetaxel treatment in PC3 cells (34) and along with its ability to palliate skeletal symptoms, it is postulated to reduce the incidence of skeletal events in patients with prostate cancer through its anti-resorptive properties (35) and also have a direct effect on the prostate cancer cells (36). Additionally, our group is currently investigating the use of PBOXs as radiosensitizing agents for advanced but localised tumours, since $\mathrm{G}_{2} / \mathrm{M}$ arrest and phosphorylation of Bcl-2 and $\mathrm{Bcl}-\mathrm{x}_{\mathrm{L}}$ by PBOXs may reduce the apoptotic threshold of tumour cells and hence render them more susceptible to death stimuli such as radiation. It may also prove beneficial to assess the effects of PBOXs alone and in combination with other compounds specifically in docetaxel-resistant prostate cancer cells.

In summary, our results to date indicate that PBOX compounds either alone or in combination may prove useful in the treatment of advanced hormone-refractory prostate cancer.

\section{Acknowledgements}

This study was funded by The Irish Cancer Society and Science Foundation Ireland. We thank Dr Orla Hanrahan for her assistance with the fluorescence microscopy.

\section{References}

1. Jemal A, Siegel R, Ward E, Hao Y, Xu J, Murray T and Thun MJ: Cancer statistics, 2008. CA Cancer J Clin 58: 71-96, 2008.

2. Fizazi K, Sternberg CN, Fitzpatrick JM, Watson RW and Tabesh M: Role of targeted therapy in the treatment of advanced prostate cancer. BJU Int 105: 748-767, 2010.

3. Tannock IF, de Wit R, Berry WR, Horti J, Pluzanska A, Chi KN, Oudard S, Théodore C, James ND, Turesson I, Rosenthal MA and Eisenberger MA: Docetaxel plus prednisone or mitoxantrone plus prednisone for advanced prostate cancer. N Engl J Med 351: 1502-1512, 2004

4. Petrylak DP, Tangen CM, Hussain MH, Lara PN Jr, Jones JA, Taplin ME, Burch PA, Berry D, Moinpour C, Kohli M, Benson MC, Small EJ, Raghavan D and Crawford ED: Docetaxel and estramustine compared with mitoxantrone and prednisone for advanced refractory prostate cancer. N Engl J Med 351: 1513-1520, 2004

5. Zisterer DM, Campiani G, Nacci V and Williams DC: Pyrrolo1,5-benzoxazepines induce apoptosis in HL-60, Jurkat, and Hut-78 cells: a new class of apoptotic agents. J Pharmacol Exp Ther 293: 48-59, 2000.

6. Mc Gee MM, Campiani G, Ramunno A, Fattorusso C, Nacci V, Lawler M, Williams DC and Zisterer DM: Pyrrolo-1,5benzoxazepines induce apoptosis in chronic myelogenous leukemia (CML) cells by bypassing the apoptotic suppressor bcr-abl. J Pharmacol Exp Ther 296: 31-40, 2001.

7. McGee MM, Campiani G, Ramunno A, Nacci V, Lawler M, Williams DC and Zisterer DM: Activation of the c-Jun Nterminal kinase (JNK) signaling pathway is essential during PBOX-6-induced apoptosis in chronic myelogenous leukemia (CML) cells. J Biol Chem 277: 18383-18389, 2002.

8. McGee MM, Greene LM, Ledwidge S, Campiani G, Nacci V, Lawler M, Williams DC and Zisterer DM: Selective induction of apoptosis by the pyrrolo-1,5-benzoxazepine 7-[[dimethylcarbamoyl]oxy]-6-(2-naphthyl)pyrrolo-[2,1-d] $(1,5)$-benzoxazepine (PBOX-6) in leukemia cells occurs via the c-Jun $\mathrm{NH}_{2}$-terminal kinase-dependent phosphorylation and inactivation of Bcl-2 and Bcl- $\mathrm{xL}$. J Pharmacol Exp Ther 310: 1084-1095, 2004.
9. McGee MM, Hyland E, Campiani G, Ramunno A, Nacci V and Zisterer DM: Caspase-3 is not essential for DNA fragmentation in MCF-7 cells during apoptosis induced by the pyrrolo-1,5benzoxazepine, PBOX-6. FEBS Lett 515: 66-70, 2002.

10. Nathwani SM, Butler S, Meegan MJ, Campiani G, Lawler M, Williams DC and Zisterer DM: Dual targeting of tumour cells and host endothelial cells by novel microtubule-targeting agents, pyrrolo-1,5-benzoxazepines. Cancer Chemother Pharmacol 65: 289-300, 2010.

11. Greene LM, Fleeton M, Mulligan J, Gowda C, Sheahan BJ, Atkins GJ, Campiani G, Nacci V, Lawler M, Williams DC and Zisterer DM: The pyrrolo-1,5-benzoxazepine, PBOX-6, inhibits the growth of breast cancer cells in vitro independent of estrogen receptor status, and inhibits breast tumour growth in vivo. Oncol Rep 5: 1357-1363, 2005.

12. Bright SA, McElligott AM, O'Connell JW, O'Connor L, Carroll P, Campiani G, Deininger MW, Conneally E, Lawler M, Williams DC and Zisterer DM: Novel pyrrolo-1,5benzoxazepine compounds display significant activity against resistant chronic myeloid leukaemia cells in vitro, in ex vivo patient samples and in vivo. Br J Cancer 102: 1474-1482, 2010.

13. McElligott AM, Maginn EN, Greene LM, McGuckin S, Hayat A, Browne PV, Butini S, Campiani G, Catherwood MA, Vandenberghe E, Williams DC, Zisterer DM and Lawler M: The novel tubulin-targeting agent pyrrolo-1,5-benzoxazepine-15 induces apoptosis in poor prognostic subgroups of chronic lymphocytic leukemia. Cancer Res 69: 8366-8375, 2009.

14. Nathwani SM, Butler S, Fayne D, McGovern NN, Sarkadi B, Meegan MJ, Lloyd DG, Campiani G, Lawler M, Williams DC and Zisterer DM: Novel microtubule-targeting agents, pyrrolo1,5-benzoxazepines, induce apoptosis in multi-drug-resistant cancer cells. Cancer Chemother Pharmacol 66: 585-596, 2010.

15. Mulligan JM, Greene LM, Cloonan S, Mc Gee MM, Onnis V, Campiani G, Fattorusso C, Lawler M, Williams DC and Zisterer DM: Identification of tubulin as the molecular target of pro-apoptotic pyrrolo-1,5-benzoxazepines. Mol Pharmacol 70: 60-70, 2006.

16. Greene LM, Campiani G, Lawler M, Williams DC and Zisterer DM: BubR1 is required for a sustained mitotic spindle checkpoint arrest in human cancer cells treated with tubulintargeting pyrrolo-1,5-benzoxazepines. Mol Pharmacol 73: 419-430, 2008.

17. Campiani G, Nacci V, Fiorini I, De Filippis MP, Garofalo A, Ciani SM, Greco G, Novellino E, Williams DC, Zisterer DM, Woods MJ, Mihai C, Manzoni C and Mennini T: Synthesis, biological activity, and SARs of pyrrolobenzoxazepine derivatives, a new class of specific 'peripheral-type' benzodiazepine receptor ligands. J Med Chem 39: 3435-3450, 1996.

18. Chou TC and Talalay P: Quantitative analysis of dose-effect relationships: the combined effects of multiple drugs or enzyme inhibitors. Adv Enzyme Regul 22: 27-55, 1984.

19. Mulligan JM, Campiani G, Ramunno A, Nacci V and Zisterer DM: Inhibition of G1 cyclin-dependent kinase activity during growth arrest of human astrocytoma cells by the pyrrolo-1,5-benzoxazepine, PBOX-21. Biochim Biophys Acta 1639: 43-52, 2003.

20. Bright SA, Greene LM, Greene TF, Campiani G, Butini S, Brindisi M, Lawler M, Meegan MJ, Williams DC and Zisterer DM: The novel pyrrolo-1,5-benzoxazepine, PBOX21, potentiates the apoptotic efficacy of STI571 (imatinib mesylate) in human chronic myeloid leukaemia cells. Biochem Pharmacol 77: 310-321, 2009.

21. Galletti E, Magnani M, Renzulli ML and Botta M: Paclitaxel and docetaxel resistance: molecular mechanisms and development of new generation taxanes. Chem Med Chem 2: 920-942, 2007.

22. Logarinho E, Bousbaa H, Dias JM, Lopes C, Amorim I, Antunes-Martins A and Sunkel CE: Different spindle checkpoint proteins monitor microtubule attachment and tension at kinetochores in Drosophila cells. J Cell Sci 117: 1757-1771, 2004.

23. Chan GK, Jablonski SA, Sudakin V, Hittle JC and Yen TJ: Human BubR1 is a mitotic checkpoint kinase that monitors CENP-E functions at kinetochores and binds the cyclosome/ APC. J Cell Biol 146: 941-954, 1999.

24. Mollinedo F and Gajate C: Microtubules, microtubule-interfering agents and apoptosis. Apoptosis 8: 413-450, 2003.

25. Fahy BN, Schlieman MG, Mortenson MM, Virudachalam S and Bold RJ: Targeting BCL-2 overexpression in various human malignancies through NF-kappaB inhibition by the proteasome inhibitor bortezomib. Cancer Chemother Pharmacol 56: 46-54, 2005. 
26. McDonell TJ, Troncoso P, Brisbay SM, Logothesis C, Chang LWK, Hsieh JT, Tu SM and Campbell ML: Expression of the proto-oncogene bcl-2 in the prostate and its association with emergence of androgen-independent prostate cancer. Cancer Res 52: 6940-6944, 1992.

27. Castilla C, Congregado B, Chinchón D, Torrubia FJ, Japón MA and Sáez C: Bcl-xL is overexpressed in hormone-resistant prostate cancer and promotes survival of $\mathrm{LNCaP}$ cells via interaction with proapoptotic Bak. Endocrinology 147: 4960-4967, 2006.

28. Tang C, Willingham MC, Reed JC, Miyashita T, Ray S, Ponnathpur V, Huang Y, Mahoney ME, Bullock G and Bhalla K: High levels of p26BCL-2 oncoprotein retard taxol-induced apoptosis in human pre-B leukemia cells. Leukemia 8: 1960$1969,1994$.

29. Ibrado AM, Liu L and Bhalla K: Bcl-xL overexpression inhibits progression of molecular events leading to paclitaxel-induced apoptosis of human acute myeloid leukemia HL-60 cells. Cancer Res 57: 3115-3120, 1997.

30. Ling YH, Tornos C and Perez-Soler R: Phosphorylation of Bcl-2 is a marker of $\mathrm{M}$ phase events and not a determinant of apoptosis. J Biol Chem 273: 18984-18991, 1998.

31. Schafer K: The cell cycle: a review. Vet Pathol 35: 461-478, 1998.
32. Bright SA, Campiani G, Deininger MW, Lawler M, Williams DC and Zisterer DM: Sequential treatment with flavopiridol synergistically enhances pyrrolo-1,5-benzoxazepine-induced apoptosis in human chronic myeloid leukaemia cells including those resistant to imatinib treatment. Biochem Pharmacol 80: 31-38, 2010.

33. Fornier MN, Rathkopf D, Shah M, Patil S, O'Reilly E, Tse AN, Hudis C, Lefkowitz R, Kelsen DP and Schwartz GK: Phase I dose-finding study of weekly docetaxel followed by flavopiridol for patients with advanced solid tumors. Clin Cancer Res 13: 5841-5846, 2007.

34. Morgan C, Lewis PD, Jones RM, Bertelli G, Thomas GA and Leonard RC: The in vitro anti-tumour activity of zoledronic acid and docetaxel at clinically achievable concentrations in prostate cancer. Acta Oncol 46: 669-677, 2007.

35. Saad F, Gleason DM, Murray R, Tchekmedyian S, Venner P, Lacombe L, Chin JL, Vinholes JJ, Goas JA and Chen B: A randomized, placebo-controlled trial of zoledronic acid in patients with hormone-refractory metastatic prostate carcinoma. J Natl Cancer Inst 94: 1458-1468, 2002.

36. Coxon JP, Oades GM, Kirby RS and Colston KW: Zoledronic acid induces apoptosis and inhibits adhesion to mineralized matrix in prostate cancer cells via inhibition of protein prenylation. BJU Int 94: 164-170, 2004. 